\title{
Correction: Hesp et al., Chronic Oligodendrogenesis and Remyelination after Spinal Cord Injury in Mice and Rats
}

In the article "Chronic Oligodendrogenesis and Remyelination after Spinal Cord Injury in Mice and Rats" by Zoe C. Hesp, Evan A. Goldstein, Carlos J. Miranda, Brain K. Kaspar, and Dana M. McTigue, which appeared on pages 1274-1290 of the January 21, 2015 issue, the second author's middle initial and fourth author's first name were incorrectly listed. The corrected author line is: Zoe C. Hesp, Evan Z. Goldstein, Carlos J. Miranda, Brian K. Kaspar, and Dana M. McTigue. The names have been corrected on the online PDF version.

DOI:10.1523/JNEUROSCI.1414-15.2015 